\title{
HOT-EXTRUDED AND COLD-ROLLED TEXTURES OF THE MATRIX ALUMINUM IN DEFORMATION PROCESSED TWO-PHASE Nb/AI METAL-METAL COMPOSITES
}

\author{
L.Q. $\mathrm{CHEN}^{\mathrm{a}, \mathrm{b}, *}$ and N. KANETAKE ${ }^{\mathrm{b}}$ \\ ${ }^{a}$ Institute of Metal Research, Chinese Academy of Sciences, 72 Wenhua Road, Shenyang 110016, \\ P.R. China; ${ }^{\mathrm{b}}$ Department of Materials Processing Engineering, School of Engineering, \\ Nagoya University, Furo-cho, Chikusa-Ku, Nagoya 464-8603, Japan
}

(Received 3 May 2002)

\begin{abstract}
In this article, the powder metallurgy technique combined with flat hot-extrusion and cold rolling processes was employed to fabricate 10 and $20 \mathrm{vol} . \% \mathrm{Nb} / \mathrm{Al}$ metal-metal composite sheets. The hot-extruded and coldrolled textures of the matrix aluminum in these metal-metal composite sheets were investigated by three dimensional orientation distribution functions (ODFs) analysis. The results show that the extrusion mode and large second phase particulate metal, $\mathrm{Nb}$, have strong influence on the development of the extrusion and cold rolling textures in composites' matrix. The matrix $\mathrm{Al}$ forms $\beta$-fiber textures after flat hot extrusion, where the components consist of $\mathrm{B}^{\prime}-\{011\}\langle 322\rangle, \mathrm{S}^{\prime}-\{124\}\langle 654\rangle$ and $\mathrm{C}^{\prime}-\{113\}\langle 332\rangle$. After cold rolling process, only $\mathrm{B}^{\prime}-\{011\}\langle 322\rangle$ changed to $\mathrm{B}-\{011\}\langle 211\rangle$ while the other components remained the same. The large particles in composites affect the matrix deformation in such a way that separates the distorted or bound zones from the deformation zones, which resulted in the final cold rolling deformation textures.
\end{abstract}

Keywords: Nb/Al; Texture; Powder metallurgy; Metal-matrix composites; Extrusion; Cold rolling

\section{INTRODUCTION}

The metal-matrix composites (MMCs) are usually referred to as the metals reinforced by another component. The reinforcement can be in the form of ceramic particles, whiskers, short fibers, or continuous fibers, so the MMCs can acquire combinative properties of metals and ceramics.

Metal-matrix composites can be obtained by heavy plastic co-deformation of powdermetallurgically prepared mixtures of two (or more) components, one of which is a metal, the other one may be metallic or nonmetallic. The process of co-deformation

*Corresponding author. Tel.: (86) 24-23971752. Fax: (86) 24-23891320. E-mail: lqchen@imr.ac.cn 
leads to an anomalous increase of the strength of the composite and it is accompanied by characteristic changes of the textures of both components (see e.g. Frommeyer and Wassermann, 1976; Bergmann et al., 1978; Wassermann et al., 1978). In recent years these deformation processed metal-metal composites (DMMC) or in situ metal-metal composites received much attention due to their anomalous strength and excellent thermal and electric conductivity (e.g. Russell et al., 1995; Raabe and Hangen, 1996; Han et al., 1999; Hong and Hill, 2000a; Xu et al., 2001).

Generally, a DMMC is composed of two immiscible metals or those having negligible solid solubility at up to its processing temperature, i.e. there is no intermetallic compounds within the binary systems. The starting material of the DMMC is usually a billet that has been prepared by casting or powder metallurgy (PM) technique and the subsequent large plastic deformation processing techniques, e.g. extrusion, swaging, drawing or rolling, could then be exerted to obtain the final metal-metal composite products. The $\mathrm{Cu}-\mathrm{Nb}$ (e.g. Bevk et al., 1978; Brandao and Kalu, 1998; Sauvage, et al., 1999, 2001), Cu-Cr (Jin et al., 1996), Al-Ti (Russell et al., 1999), Al-Nb (Thieme et al., 1993) are some of the representative composites and thus the most thoroughly investigated metal-metal systems.

For the DMMC finely dispersed with the second metal, the usual rule of mixture $(\mathrm{ROM})$ is not applicable for characterizing their mechanical properties, since the experimentally measured tensile properties deviate strongly from the ROM (see e.g. Thieme et al., 1993; Russell et al., 1999). Besides the work-hardening effect caused by high degree of cold plastic deformation during composite fabrication, the other reason for the increase in tensile strength is generally believed to be resulted from the texture effect of the reinforcement and matrix metals, especially the textures in reinforcement metal (see e.g. Bevk et al., 1978; Russell et al., 1995, 1999). For example, in the $\mathrm{Cu}-X$ deformation processed composites ( $X$ refers to the bcc transition metal second phase insoluble in $\mathrm{Cu})$, the second phase typically forms a $\langle 111\rangle$ fiber texture often accompanied by a $\langle 001\rangle$ fiber texture, two of the four $\langle 111\rangle$ directions (the [1 $\overline{1} 1]$ and the [ $\overline{1} \overline{1} 1]$ are positioned perpendicular to the center line and thus cannot slip. All slip is limited to the remaining two $\langle 111\rangle$ directions (the [1 11] and the [111] which lie opposite one another across the specimen center line, thus limiting the bcc phase to plane strain. The fcc $\mathrm{Cu}$ matrix, however, can readily deform axisymmetrically in either the $\langle 111\rangle$ or $\langle 001\rangle$ fiber texture, since these orientations possess three and four slip directions, respectively, to accommodate plastic flow. For cold-swaged Al-Ti (Russell et al., 1999) and Al-Mg composites (Xu et al., 1999) the microstructures are quite similar to that of $\mathrm{Cu}-X$ DMMC's. The $\langle 10 \overline{1} 0\rangle$ fiber texture was measured in the hcp Ti phase of the Al-Ti DMMC's, and no clear texture was observed in the hcp $\mathrm{Mg}$ second phase of the Al-Mg specimens.

The metal-metal composites in the form of wire could be obtained by processing techniques, such as drawing or swaying, etc., and presently there are many reports on the fabricating processes, microstructures, mechanical properties and strengthening mechanism for this kind of MMC (e.g. Thieme et al., 1993; Snoeck et al., 1998; Russell et al., 1999; Hong and Hill, 2000b; Chung et al., 2001). Concerning the sheet metal-metal composites, however, there is little appeared associating with the rolling technology. For pure fcc metals or alloys, their rolling textural characteristics have been well documented (e.g. Hu and Cline, 1988). However, for two-phase immiscible metal systems or large metal particulate reinforced metal-metal composites, there is a requirement to understand the textural development process in matrix or how they 
are affected with the existence of the second reinforcement metal during cold working process or recrystallization.

Therefore, in this study the rolling processing technique for manufacturing the MMCs sheet is briefly introduced and the emphasis is focused on the investigation of the deformation textural evolution of the matrix aluminum for the rolling processed two-phase $\mathrm{Nb} / \mathrm{Al}$ metal-metal composite at stages of extrusion and cold rolling.

\section{EXPERIMENTAL}

In this study the typical powder metallurgy method was employed to fabricate the starting billets of DMMCs at first and the hot extrusion and cold rolling technologies were then used to produce MMCs sheet.

The raw materials are $\mathrm{Al}$ and $\mathrm{Nb}$ powders. The matrix $\mathrm{Al}$ powder has a mean particle size of $45 \mu \mathrm{m}$ and a purity of $99.7 \%$, and the $\mathrm{Nb}$ particulate powder used as reinforcement possess an average size of $300 \mu \mathrm{m}$ ( $99.9 \%$ purity). The $\mathrm{Al}$ and $\mathrm{Nb}$ powders $(90: 10$ and 80:20, in volume percentage) were mechanically mixed with a V-type blending machine for $10 \mathrm{~h}$. After being consolidated at room temperature with a pressure of $700 \mathrm{MPa}$ for $1 \mathrm{~min}$, the cylindrical composite billets of $40 \mathrm{~mm}$ in diameter were extruded into $10 \times 4 \mathrm{~mm}$ slab composites at $773 \mathrm{~K}$ with an extrusion ratio of $31: 1$. The multipass cold rolling process was finally used to produce composite plate at room temperature in a two-roller mill.

Texture measurement (specimen's central layer) of the composites was conducted on a fully automatic X-ray diffractometer (RINT-2000, Japan). The texture specimens were prepared by mechanical grinding and then electrolytically polished to a final thickness of about $0.15 \mathrm{~mm}$. As the X-ray diffraction peaks of $\mathrm{Al}\{111\}$ and $\mathrm{Nb}\{110\}$ are totally overlapped, the planes of $\mathrm{Al}\{200\},\{220\}$, and $\{311\}$ were selected to measure its complete pole figures by Schulz's reflection method combined with Deck's transmission method. The normalized pole figures data were obtained after compensating the absorption and defocusing and deduction background. The ODFs calculated by series expansion method $\left(L_{\max }=22\right)$ were presented as constant $\varphi 2$ sections.

\section{RESULTS AND DISCUSSIONS}

Figure 1 shows the experimentally measured constant $\varphi 2$ ODF sections of the matrix aluminum for the extruded 10 and 20 vol. $\% \mathrm{Nb} / \mathrm{Al}$ metal-metal composites at $773 \mathrm{~K}$.

One can observe from Fig. 1(a) and (b) that there formed the hot-extrusion textures within the matrix aluminum of the $\mathrm{Nb} / \mathrm{Al}$ composite at extruding temperature of $773 \mathrm{~K}$. The extrusion texture can be described by superposition of orientations, whose ODFs in the Euler space are also depicted by the texture " $\beta$ '-tube" similar to the cold rolling textures in fcc metals. For the present flat-extruded composite specimen, this texture tube $\beta$-fiber contains the components of $\mathrm{B}^{\prime}-\{011\}\langle 322\rangle, \mathrm{S}^{\prime}-\{124\}\langle 654\rangle$, and $C^{\prime}-\{113\}\langle 332\rangle$, which is totally different from the typically extruded axial fiber textures in fcc metals resulted from axisymmetric extrusion deformation and similar to the result for flat extruded aluminum alloy reported by Inoue (2002).

It is well known that the textures in a cold-rolled fcc metals can be represented by a $\beta$-fiber, i.e. B- $\{011\}\langle 211\rangle, \mathrm{S}-\{123\}\langle 634\rangle$ and $\mathrm{C}-\{112\}\langle 111\rangle$, which is produced by the 


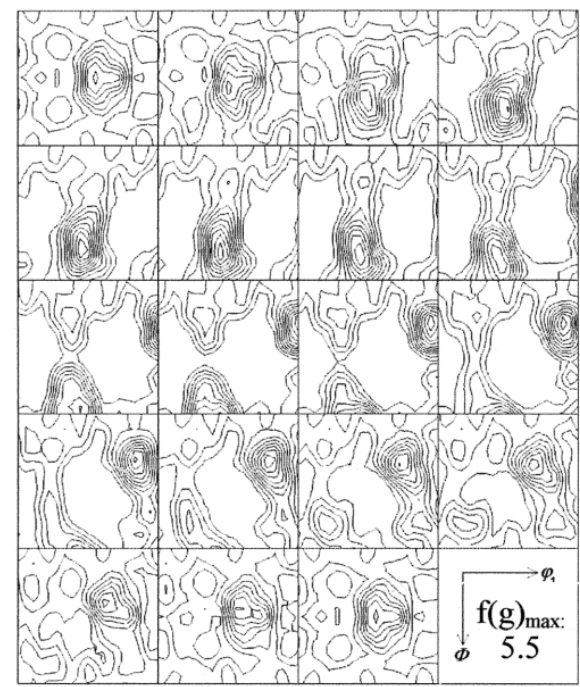

(a)

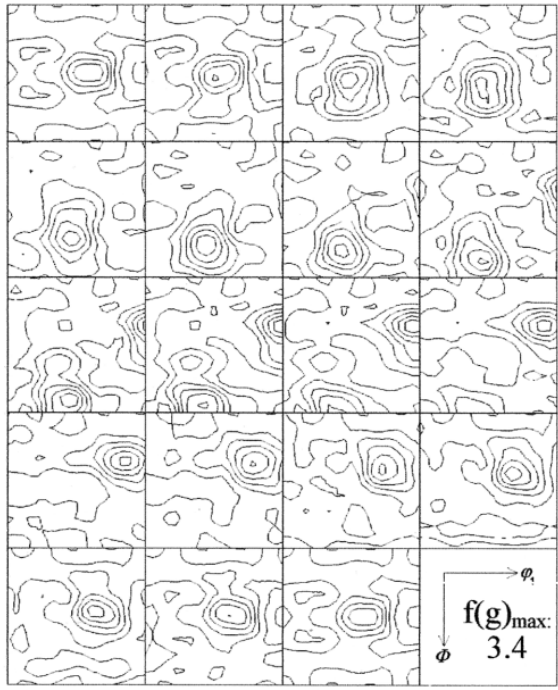

(b)

FIGURE 1 The flat-extruded textures of the matrix in $\mathrm{Nb} / \mathrm{Al}$ metal-metal matrix composites; constant $\varphi 2$ sections of the ODF: (a) $10 \mathrm{vol} . \% \mathrm{Nb} / \mathrm{Al}$; (b) $20 \mathrm{vol} . \% \mathrm{Nb} / \mathrm{Al}$; (level intensities: $0.5,1.0,1.5, \ldots, \times$ random).

plane strain compressive deformation during cold rolling process. The specimens under the present extrusion condition will be co-compressed or contracted in the normal directions of the flat plane, while elongated along the longitudinal or extruding direction. In such a case, the deformation state is close to the plane strain compression behavior without widening, which would lead to the $\beta^{\prime}$-fiber texture and also slightly deviate from the normal $\beta$-fiber. For both the 10 and $20 \mathrm{vol} . \% \mathrm{Nb} / \mathrm{Al}$ composites, the similar texture components were observed existing in the matrix $\mathrm{Al}$ and only the difference in the orientation density could be noticed. The component $\mathrm{B}^{\prime}\{011\}\langle 322\rangle$ appeared in the composite is very close to the Brass component $\{011\}\langle 211\rangle$ with $8^{\circ}$ mutual rotation about the normal direction of $\{011\}$ plane. As for the other components, $\mathrm{S}^{\prime}$ and $\mathrm{C}^{\prime}$, they both are not far from the standard orientations of the $\mathrm{S}$ and $\mathrm{C}$ components. One can also observe that there is a weakening tendency with increasing the volume percentage of the reinforcement $\mathrm{Nb}$. Besides the $\beta^{\prime}$-fiber, there were no other strong texture components within the extruded matrix aluminum of the composite.

As we know, the Cube recrystallization textures $\{001\}\langle 100\rangle$ usually occurs during annealing for high or medium stacking fault energy fcc metals. Due to the absence of Cube texture in the present case, however, we can deduce that no recrystallization or dynamic recrystallization took place during hot-extrusion process.

The 10 and $20 \mathrm{vol} . \% \mathrm{Nb} / \mathrm{Al}$ metal-metal matrix composite sheets were obtained by multipass rolling at room temperature along the extruded direction and the textures of the matrix Al were revealed by representation of the ODFs shown in Figs. 2 and 3, respectively. From Fig. 2 it can be seen that their orientation densities tend to be enhanced with increasing the total cold rolling reductions, especially at lower volume content of the reinforcement (e.g. $10 \mathrm{vol} . \% \mathrm{Nb}$ ). On the other hand, the locations of the main texture components change with the strengthening of the $\beta$-fiber texture. 


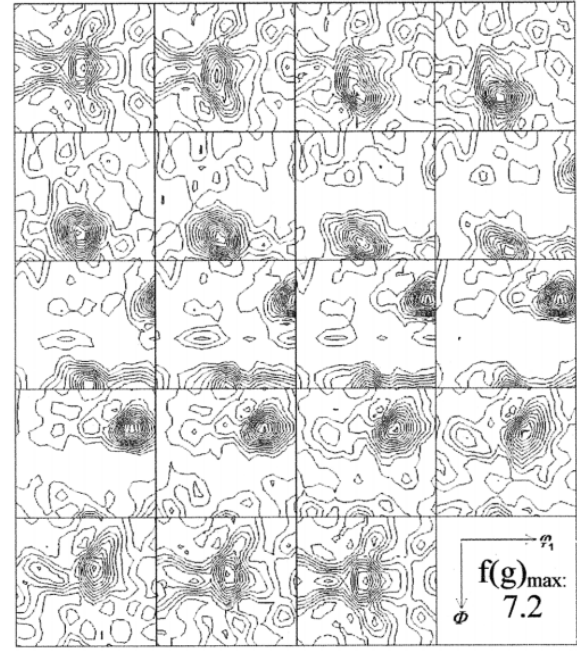

(a)

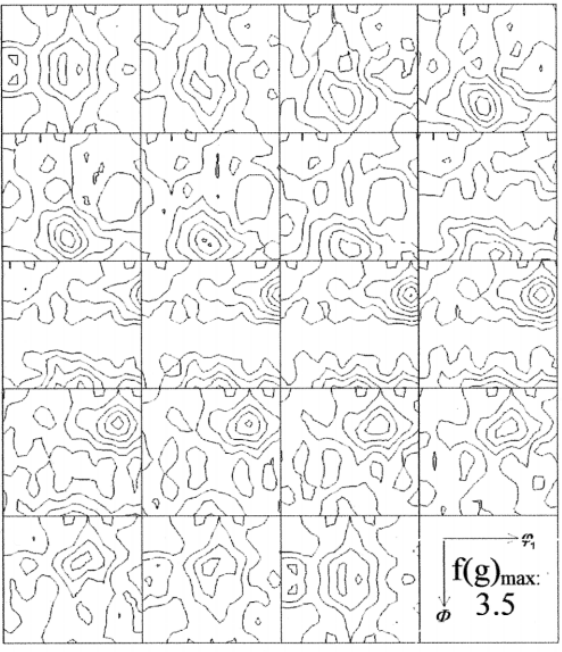

(b)

FIGURE 2 Cold rolling textures of the matrix in $\mathrm{Nb} / \mathrm{Al}$ metal-metal matrix composites at $50 \%$ CRR; constant $\varphi 2$ sections of the ODF: (a) $10 \mathrm{vol} \% \mathrm{Nb} / \mathrm{Al} ;$ (b) $20 \mathrm{vol} . \% \mathrm{Nb} / \mathrm{Al}$; (level intensities: $0.5,1.0,1.5, \cdots, \times$ random $)$.

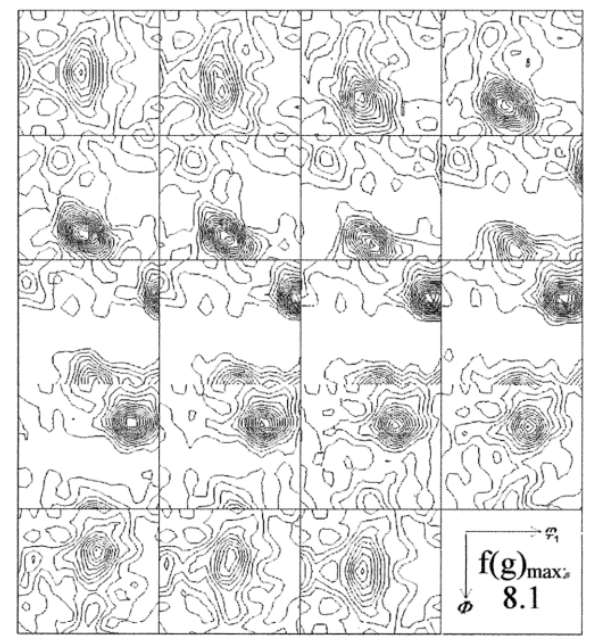

(a)

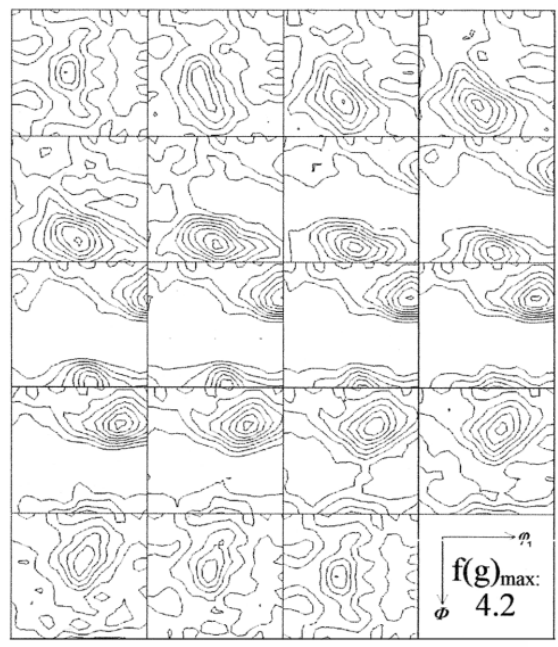

(b)

FIGURE 3 Cold rolling textures of the matrix in $\mathrm{Nb} / \mathrm{Al}$ metal-metal matrix composites at $80 \%$ CRR; constant $\varphi 2$ sections of the ODF: (a) $10 \mathrm{vol} \% \mathrm{Nb} / \mathrm{AL}$; (b) $20 \mathrm{vol} . \% \mathrm{Nb} / \mathrm{Al}$; (level intensities: $0.5,1.0,1.5, \ldots, \times$ random $)$.

It is evident that as the cold rolling reduction increased the texture component $\mathrm{B}^{\prime}\{011\}\langle 322\rangle$ in the $\beta^{\prime}$-fiber gradually transformed into $\mathrm{B}\{011\}\langle 211\rangle$, while the components $S^{\prime}\{124\}\langle 654\rangle$ and $C^{\prime}\{113\}\langle 332\rangle$ remained unchanged and only the orientation densities were strengthened. In the case of lower cold rolling reductions (CRR), e.g. $50 \%$, weak Goss component $\{110\}\langle 001\rangle\left\{\varphi 1=0^{\circ}, \phi=45^{\circ}, \varphi 2=0^{\circ}\right\}$ appeared in 
both 10 and $20 \mathrm{vol} \% \mathrm{Nb} / \mathrm{Al}$ composites. As the CCR reached up to $80 \%$ or more, the unstable Goss moved towards the orientation $\mathrm{B}$ in the $\beta$-fiber and a typical fcc cold rolling $\beta$-fiber texture formed within the matrix $\mathrm{Al}$ of the metal-metal matrix composites. Although there is somewhat a subtle difference in the texture details for the two-phase metal-metal matrix composites, undoubtedly this arises from the presence of the second phase particulates in the matrix, which will affect the microplastic deformation of the matrix during the cold rolling process. That is to say, the second phase particulate, especially those large-sized particulate will give rise to heterogeneity of the deformation region that lead to their independent deformation and rotation of the grains around the particulate.

Concerning the plastic deformation of the ceramic particulate reinforced aluminum composites (SiC/Al), Humphreys et al. $(1990,1991)$ emphasized that the rotations within the deformation zones in polycrystals are related to both strain and the slip systems active in the matrix. For the present composites, the $\mathrm{Nb}$ particulate is much harder than $\mathrm{Al}$ particles and also has a relatively rather large size $(\sim 300 \mu \mathrm{m})$ such that the bound zones can be formed. In addition to the formation of deformation zones, large particles are also likely to disturb the slip pattern in the matrix, resulting in a lensoid distortion of the substructure around the particle. A lensoid distortion of the substructure generally originates from the inhomogeneous deformation in matrix by multislip around the large particles with the periphery matrix shape changed in the lens-like form, which is caused by the crystal rotation around the particles. Examples of the deformation features associated with SiCp in low volume fraction aluminum composites were experimentally provided by Humphreys (1991). As a model for metal-metal composites shown in Fig. 8, larger particles can produce distorted zones and they can readily be restricted to deform around the particles. Therefore the texture in particles containing two-phase composites is not fully developed and sometimes deviates from the position of the typical orientations.

The $\alpha, \tau$ and $\beta$ orientation lines depicted in Figs. 4-7 clearly featured the texture evolution during processing of hot extrusion and cold rolling deformation for the $\mathrm{Nb} / \mathrm{Al}$ composites. As the locations of the $\beta$-fiber orientation lines in extruded 10 and $20 \mathrm{vol} . \% \mathrm{Nb} / \mathrm{Al}$ composites are almost the same, they were plotted together in Fig. 6(b). The $\alpha$-fibers at various processing states in Fig. 4(a) and (b) show that the texture orientation distribution has a scattering and no other but only

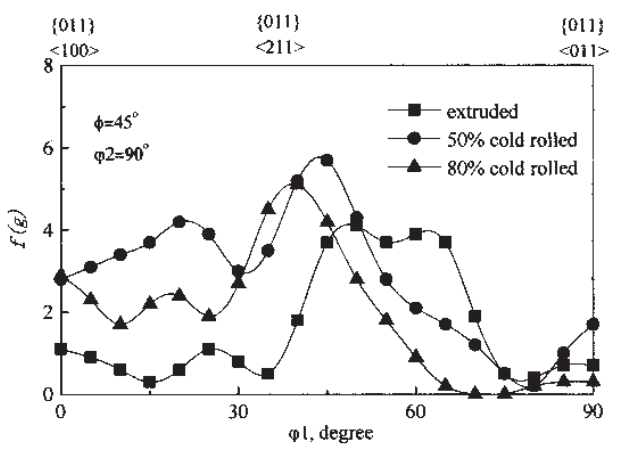

(a)

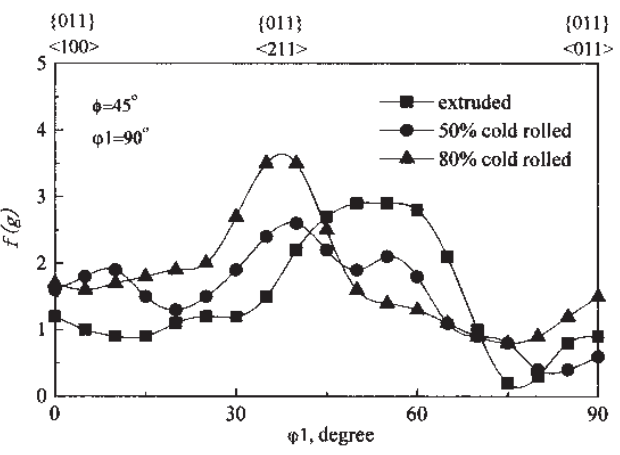

(b)

FIGURE $4 \alpha$-fiber of the matrix $\mathrm{Al}$ in the flat-extruded and cold-rolled $\mathrm{Nb} / \mathrm{Al}$ metal-metal matrix composites; (a) 10 vol. \% Nb/Al MMCs; (b) 20 vol. \% Nb/Al MMCs. 


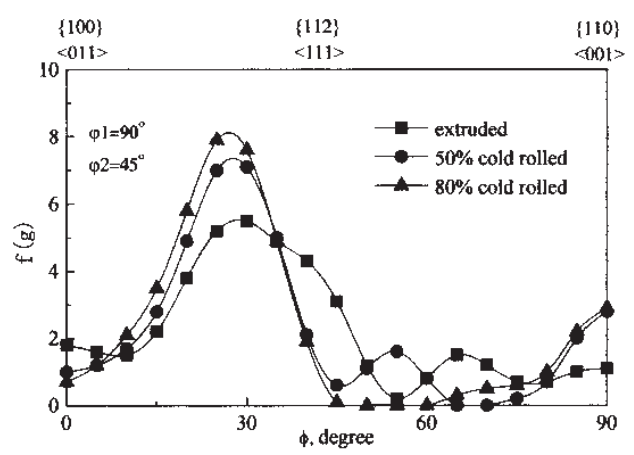

(a)

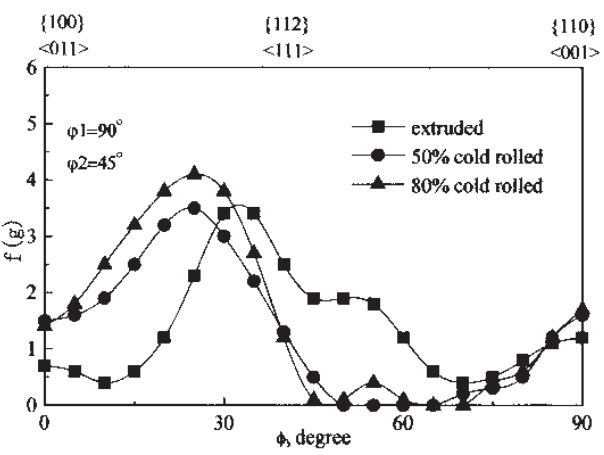

(b)

FIGURE $5 \tau$-fiber of the matrix $\mathrm{Al}$ in the flat-extruded and cold-rolled $\mathrm{Nb} / \mathrm{Al}$ metal-metal matrix composites; (a) $10 \mathrm{vol} \% \mathrm{Nb} / \mathrm{Al}$ MMCs; (b) $20 \mathrm{vol} . \% \mathrm{Nb} / \mathrm{Al} \mathrm{MMCs}$.

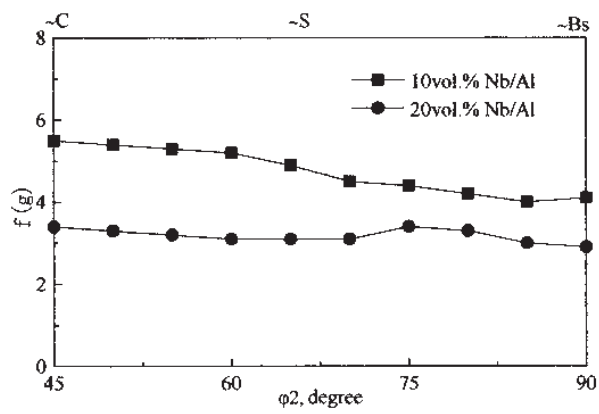

(a)

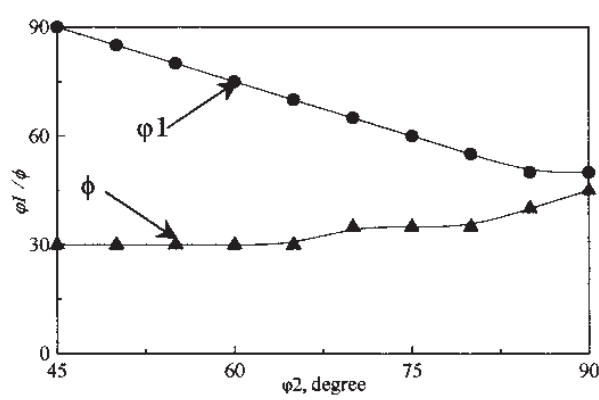

(b)

FIGURE $6 \beta$-fiber textures and their locations in Euler space for the flat-extruded $\mathrm{Nb} / \mathrm{Al}$ metal-metal matrix composites; (a) $\beta$-fiber for 10 and $20 \mathrm{vol} . \% \mathrm{Nb} / \mathrm{Al}$; (b) locations in Euler space.

$\mathrm{B}^{\prime}\{011\}\langle 322\rangle$ is remarkable at plate-extruded state. By increasing the cold rolling reduction, the $\mathrm{B}^{\prime}\{011\}\langle 322\rangle$ gradually transforms into stable $\mathrm{B}\{011\}\langle 211\rangle$ and there are random components within it. A minor $\{011\}\langle 100\rangle$ component in rolled specimen comes from the shear strain exerted during cold rolling deformation due to the existence of $\mathrm{Nb}$ particulates.

$\tau$-fiber line refers to the all orientations corresponding to $\varphi 1=90^{\circ}, \varphi 2=45^{\circ}$ and $\phi=0 \sim 90^{\circ}$. As shown in Fig. 5, it is obvious that only near Copper $C^{\prime}\{113\}\langle 332\rangle$ is dominant and stable before and after cold rolling deformation, which resulted from the lensoid distortion of the slip planes and substructure around the particulates.

\section{CONCLUSIONS}

The texture evolution of the 10 and $20 \mathrm{vol} . \% \mathrm{Nb} / \mathrm{Al}$ metal-metal matrix composite were studied by analyzing the experimentally measured ODFs at states of extrusion and cold rolling deformation. The following conclusions can be drawn:

1. The hot-extruded texture of the matrix aluminum in $\mathrm{Nb} / \mathrm{Al}$ metal-metal matrix composites can be represented by a $\beta$-fiber containing the components of 


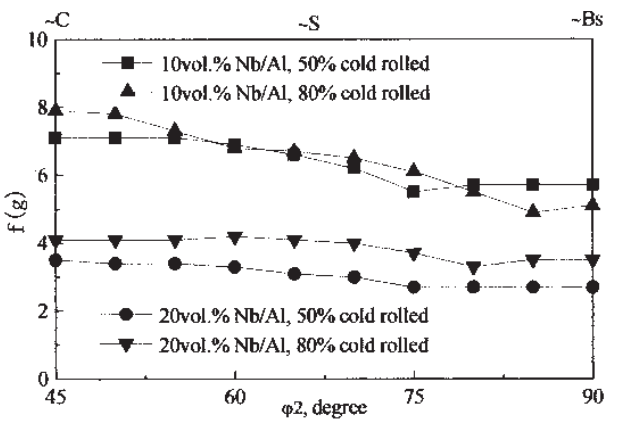

(a)

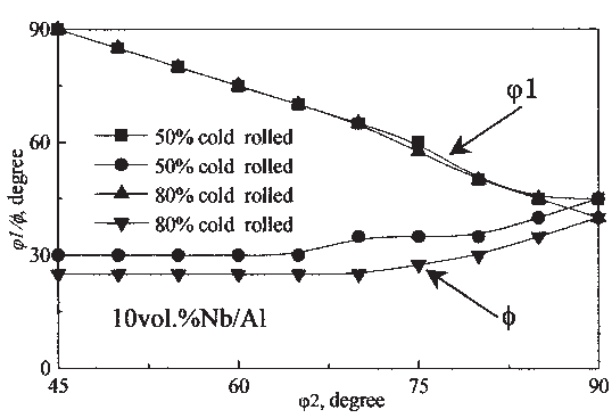

(b)

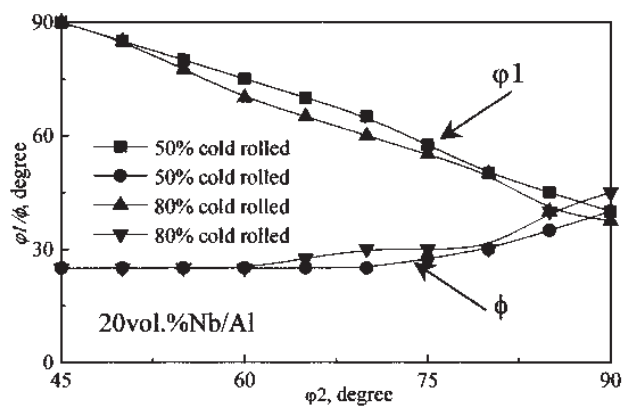

(c)

FIGURE $7 \quad \beta$-fiber textures and their locations in Euler space for the cold-rolled $\mathrm{Nb} / \mathrm{Al}$ metal-metal matrix composites; (a) $\beta$-fiber for the 10 and $20 \mathrm{vol} . \% \mathrm{Nb} / \mathrm{Al}$; (b) $\beta$-fiber locations in Euler space for $10 \mathrm{vol} . \% \mathrm{Nb} / \mathrm{Al}$ and (c) $\beta$-fiber locations in Euler space for $20 \mathrm{vol} . \% \mathrm{Nb} / \mathrm{Al}$.

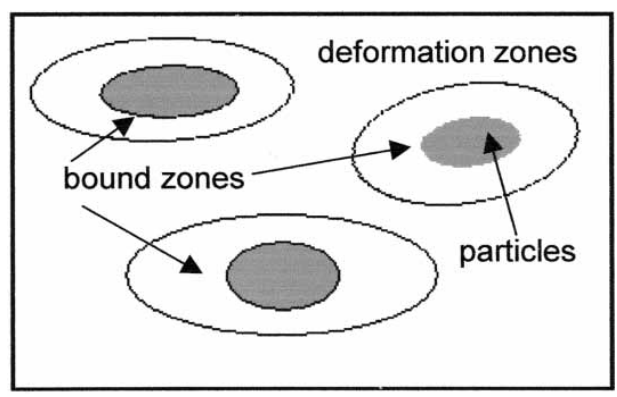

FIGURE 8 Schematic illustration showing the deformation zones and the bound zones (distorted and restricted to deform) around large particles.

$\mathrm{B}^{\prime}-\{011\}\langle 322\rangle, \mathrm{S}^{\prime}-\{124\}\langle 654\rangle$, and $\mathrm{C}^{\prime}-\{113\}\langle 332\rangle$, which is close to the $\beta$-fiber in a cold-rolled pure fcc metal.

2. When this composite was subjected to cold rolling deformation, the $\beta$-fiber texture in the matrix Al will be enhanced where the orientation components consist of $\mathrm{B}\{011\}\langle 211\rangle, \mathrm{S}^{\prime}-\{124\}\langle 654\rangle$, and $\mathrm{C}^{\prime}-\{113\}\langle 332\rangle$. 
3. By increasing the cold rolling reduction, the textures become stronger and get more stable at $\mathrm{B}, \mathrm{S}^{\prime}$ and $\mathrm{C}^{\prime}$. The second-phase particulate existing in the composites weaken the deformation texture and this effect depends mainly on the volume fraction of the particulate employed.

4. Large particulates in the metal-metal composites strongly affect the plastic deformation of the matrix $\mathrm{Al}$ in such a way that they separate the matrix into deformation zones and bound zones around the particulates. The texture deviating from the normal $\beta$-fiber $(\mathrm{B}-\{011\}\langle 211\rangle, \mathrm{S}-\{123\}\langle 634\rangle$, and $\mathrm{C}-\{112\}\langle 111\rangle)$ will be produced in the inhomogeneous deformed microstructures.

\section{Acknowledgments}

This work was performed at Laboratory of Composite Materials Engineering, Department of Materials Processing Engineering, School of Engineering, Nagoya University, Japan. A special appreciation should also be given to Dr. Y. Inoue, Nagoya University, for permitting to use the X-ray equipment. The ODF calculating software was provided by Dr. H. Inoue, Osaka Prefectural University, Japan. One of the authors (L.Q. Chen) would like to thank Dr. M. Kobashi and Dr. T. Itoh in this laboratory for providing much assistance during his stay in Japan.

\section{References}

Bergmann, H.W., Frommeyer, G. and Wassermann, G. (1978). The dependence of the texture and microstructure in two-phase composites on the yield stresses of the components. In: Gottstein, G. and Lucke, K. (Eds.), Textures of Materials, Vol. II, p. 379. (ICOTOM 5), Springer-Verlag.

Bevk, J., Harbison, J.P. and Bell, J.L. (1978). Anomalous increase in strength of in situ formed Cu-Nb multifilamentary composites. J. Appl. Phys., 49, 6031-6038.

Brandao, L. and Kalu, P.N. (1998). The effect of fabrication mode on microstructrue, texture and strengthening in $\mathrm{Cu}-\mathrm{Nb} / \mathrm{Ti}$ composite. Scripta Mater., 39, 27-33.

Chung, J.H., Song J.S. and Hong, S.I. (2001). Bundling and drawing processing of $\mathrm{Cu}-\mathrm{Nb}$ microcomposites with various Nb contents. J. Mater. Process Tech., 113, 604-609.

Frommeyer, G. and Wassermann, G. (1976). Herstellung und Eigenschaften metallischer Verbundfolien. Z. Werkstofftechn., 7, 154.

Han, K., Embury. J.D., Sims, J.R., Camphell, L.J., Schneider-Muntau, H.-J., Pantsyrnyi, V.I., Shikov, A., Nikulin, A and Vorobieva, A. (1999). The fabrication, properties and microstructure of $\mathrm{Cu}-\mathrm{Ag}$ and $\mathrm{Cu}-\mathrm{Nb}$ composite conductors. Mater. Sci. and Eng., A267, 99-114.

Hong, S.I. and Hill, M.A. (2000a). Microstructural stability of $\mathrm{Cu}-\mathrm{Nb}$ microcomposite wires fabricated by the bundling and drawing process. Mater. Sci. and Eng., A281, 189-197.

Hong, S.I. and Hill, M.A. (2000b). Mechanical properties of $\mathrm{Cu}-\mathrm{Nb}$ microcomposites fabricated by the bundling and drawing process. Scripta Mater., 42, 737-742.

$\mathrm{Hu}, \mathrm{H}$. and Cline, R.S. (1988). On the mechanism of texture transition in face centered cubic metals. Textures and Microstructures, 8-9, 191-206.

Humphreys, F.J., Miller, W.S. and Djazeb, M.R. (1990). Microstructural development during thermomechanical processing of particulate metal matrix composites. Mater. Sci. and Tech., 6, 1157-1166.

Humphreys, F.J. (1991) The thermomechanical processing of A1-SiC particulate composites. Mater. Sci. and Eng., A135, 267-273.

Inoue, H. (2002). Texture of extruded aluminum alloys. Journal of Japan Institute of Light Metals, 52, 524-529.

Jin, Y., Adachi, K., Takeuchi, T. and Suzuki, H.G. (1996). Microstructural evolution of a heavily cold-rolled $\mathrm{Cu}-\mathrm{Cr}$ in situ metal matrix composite. Mater. Sci. and Eng., A212, 149-156.

Raabe, D. and Hangen, U. (1996). Correlation of microstructure and type II superconductivity of a heavily cold rolled $\mathrm{Cu}-20 \mathrm{mass} \% \mathrm{Nb}$ in situ composite. Acta Mater., 44, 953-961.

Russell, A.M., Chumbley, L.S., Ellis, T.W., Laabs, F.C., Norris, B. and Donizetti, G.E. (1995). In situ strengthening of titanium with yittrium: texture analysis. J. Mater. Sci., 30, 4249-4262. 
Russell, A.M., Lund, T., Chumbley, L.S., Laabs, F.C., Keehner, L.L. and Harrinaga, J.L. (1999). A highstrength, high-conductivity Al-Ti deformation processed metal-metal matrix composite. Part A Composites, 30, 239-247.

Sauvage, X., Thilly, L., Lecouturier, F., Guillet, A. and Blavette, D. (1999). FIM and 3D atom probe analysis of $\mathrm{Cu} / \mathrm{Nb}$ nanocomposite wires. Nanostructured Materials, 11, 1031-1039.

Sauvage, X., Renaud, L., Deconihout, B., Blavette, D., Ping, D.H. and Hono, K. (2001). Solid state amorphization in cold drawn $\mathrm{Cu} / \mathrm{Nb}$ wires. Acta Mater., 49, 389-394.

Snoeck, E., Lecouturier, F., Thilly, L., Casanove, M.J., Rakoto, H., Coffe, G., Askenazy, S., Peyrade, J.P., Roucau, C., Pantsyrny, V., Shikov, A. and Nikulin, A. (1998). Microstructural studies of in situ produced filamentary $\mathrm{Cu} / \mathrm{Nb}$ wires. Scripta Mater., 38, 1643-1648.

Thieme, C.L.H., Pourrahimi, S. and Foner, S. (1993). High strength A1 metal-matrix microcomposite wire with 20 vol. $\% \mathrm{Nb}$ and ultimate tensile strength up to $1030 \mathrm{MPa}$. Scripta Metall et Mater., 28, 913-918.

Wassermann, G., Bergmann, H.W. and Frommeyer, G. (1978). Deformation textures in two-phase systems. In: Gottstein, G. and Lucke, K. (Eds.), Textures of Materials, Vol. II, p. 37. (ICOTOM 5), SpringerVerlag.

Xu, K., Russell, A.M., Chumbley, L.S., Laabs, F.C., Gantovnik, V. and Tian, Y. (1999). Characterization of strength and microstructure in deformation processed Al-Mg composites. J. Mater. Sci., 34, 5955-5959.

Xu, K., Russell, A.M., Chumbley, L.S. and Laabs, F.C. (2001). A deformation processed Al-20\% Sn in situ composite. Scripta Mater., 44, 935-940. 